\title{
Fishing for iodine: what aquatic foraging by bonobos tells us about human evolution
}

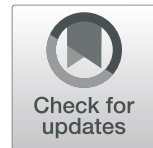

Gottfried Hohmann 1* (D), Sylvia Ortmann², Thomas Remer ${ }^{3}$ and Barbara Fruth ${ }^{4,5}$

\begin{abstract}
Background: Expansion of brain tissue and development of advanced cognitive skills are characteristic traits of human evolution. Their emergence has been causally linked to the intake of nutrients that promote brain development and iodine is considered a critical resource. Rich sources of iodine exist in coastal areas and evolutionary scenarios associate the progressive development of brain size and cognitive skills to such landscapes. This raises the question of how early hominins living in continental areas could have met their iodine requirements. One way to explore this question is to use information from hominoid primates as a proxy for the nutritional ecology of early hominins. Bonobos are particularly interesting in this context as they are restricted to the central part of the Congo basin, an area considered to be iodine deficient based on human standards.

Methods: Pooled samples of fruit, terrestrial and aquatic herbs were used to assess mineral content with an inductively coupled plasma optical emission spectrometer. lodine content was measured with the catalytic technique of Sandell-Kolthoff and two separate inductively coupled plasma mass spectrometry methods.

Results: Nutritional analyses revealed that the mineral content of aquatic herbs is higher than in other plant foods. Moreover, two species of aquatic herbs consumed by bonobos contain iodine concentrations that are almost equivalent to marine algae.

Conclusions: These data challenge the general notion that the Congo basin is iodine deficient and demonstrate that its lowland forest offers natural sources of iodine in concentrations high enough to prevent iodine deficiency in hominoids and humans.
\end{abstract}

Keywords: lodine, Aquatic herbs, Congo basin, Bonobo, Pan paniscus

\section{Background}

Among the key traits that are associated with human evolution are the progressive expansion of brain tissue and the development of advanced communicative and cognitive skills. The emergence of these traits has been causally linked to the intake of nutrients that promote brain development, as well as to those that protect hominids from shortages in energy supply $[1,2]$. The progressive encephalization reflects the synergistic effects of a number of nutritional parameters, including a diet that contains essential elements for brain growth such as long-chained polyunsaturated fatty acids, arachidonic acid, eicosapentaenoic acid, and specific trace elements [3-5]. Amongst the latter, iodine is considered

\footnotetext{
* Correspondence: hohmann@eva.mpg.de

${ }^{1}$ Max Planck Institute for Evolutionary Anthropology, Deutscher Platz 6, 04103

Leipzig, Germany

Full list of author information is available at the end of the article
}

critical for development, health, and reproduction in modern humans and early hominids [6, 7]. Given that adequate iodine intake promotes brain development and other developmental traits by ensuring appropriate thyroid hormone production and availability, it is reasonable to assume that enhanced intake of iodine was a prerequisite for the functional expansion of brain tissue, its structural differentiation, and the related social and cognitive skills. The sensitivity to iodine deficiency shown by modern humans raises the question of how and from where did early hominins obtain iodine to satisfy their needs and prevent deleterious symptoms of iodine deficiency.

One premise in most models of human evolution is a change in diet, namely a shift from a plant-based to a more omnivorous diet consisting of both plants and larger fauna [8], and in addition a shift from arboreal

(c) The Author(s). 2019 Open Access This article is distributed under the terms of the Creative Commons Attribution 4.0 International License (http://creativecommons.org/licenses/by/4.0/), which permits unrestricted use, distribution, and 
plant foods (C3) to terrestrial plants of open habitats (C4) [9]. Adopting the notion that the procurement of "brain-selective nutrients" [7] was primed by the consumption of foods that do not require the advanced cognitive skills of contemporary hunter-gatherers, information from hominoid primates and their diets may shed light on the way that prehistoric hominins may have improved their iodine intake. Great ape species (Hominidae) are characterized by a relatively large brain that undergoes complex structural development during pre- and postnatal ontogeny $[10,11]$. They experience a long phase of physical and social dependency during which they develop advanced social and cognitive skills $[12,13]$. While all ape species are omnivorous to some extent, the diet of bonobos (Pan paniscus) and chimpanzees ( $P$. troglodytes) shows some remarkable similarities to that of humans (Homo sapiens): Both species feed on leaves, herbs, and a variety of energy rich plant foods such as fruit pulp and seeds [14]. Some populations dig for roots and other underground organs [15], extract honey from tree holes and burrows $[16,17]$, feed on insects $[18,19]$, and consume meat of other vertebrates [20, 21]. Although some populations engage in crop raiding, the overall impact of cultivated plant foods can be considered negligible, which means that natural food items are sufficient for meeting nutritional requirements. More specifically, the natural diet of bonobos and chimpanzees contains sufficient amounts of iodine to support normative patterns of growth, social and cognitive development, and reproduction. Many populations of bonobos and chimpanzees inhabit areas considered to be iodine deficient based on human standards but it is reasonable to assume that sources of environmental iodine used by apes are sufficient to prevent the detrimental effects of iodine deficiencies that affect human populations living in the same environment. However, one caveat of this statement is the lack of information about the requirement of dietary iodine by any of the great ape species. Another caveat concerns the lack of information about the iodine content in the natural diet of hominoid primates.

This study reports on iodine concentrations of plant foods consumed by wild bonobos, a hominoid species endemic to the central Congo basin. Answering questions regarding how wild living hominoid primates obtain iodine from natural food sources is crucial for a better understanding of (I) the nutritional constraints that tropical forest environments exert on nonhuman primates, (II) the strategies of consumers to cope with this challenge, and (III) the related fitness consequences. Moreover, understanding how hominoid primates living in a continental forest environment meet their iodine intake is of general interest as it may explain how prehistoric hominins obtained iodine in concentrations that were not only sufficient in terms of lowest basic requirements but also for the neural and cognitive developments that are thought to be contingent on increasing amounts of dietary iodine.

\section{Results \\ Mineral content}

Table 1 shows the results of mineral analyses of various plant foods including ripe fruit $(N=7)$, leaves of ligneous plants $(N=1)$ and terrestrial $(\mathrm{N}=1)$ and aquatic herbs $(N=2)$. Overall, mineral content was higher in herbs compared to fruit, and out of the eight minerals analyzed, aquatic herbs had the highest values in six of them. The maximum value for Zinc ( $\mathrm{Zn}$ ) was found in the sample of a woody vine and that for Natrium $(\mathrm{Na})$ in the leaves of Dialium spp. trees. Likewise, the two aquatic herbs contained the highest amounts of iodine. Comparing measures of iodine content obtained using different analytical techniques by three independent labs shows high correspondence of iodine content (Table 1).

\section{Feeding behavior and ranging}

LuiKotale bonobos feed on plant foods such as fruit from ligneous plants and terrestrial and aquatic herbs. Fruit eating accounts for $>60 \%$ of feeding time and is largely an arboreal activity. Fruit availability fluctuates in terms of number as well as species of fruiting trees/vines and food patches are often widely dispersed. Terrestrial herbs, also known as terrestrial herbaceous vegetation (THV sensu [22]), are available year-round, are consumed daily, and are relatively evenly distributed across the forest. Availability of aquatic herbs is limited to one Bai in the South of the range of one community, and to riverine ponds of a larger river that forms the northern border of the ranges of both communities. Records from one community covering 2 years show that bonobos consumed aquatic herbs once every 2 weeks on average (36 times in 517 observation days, spread over 13 months). Foraging visits to the swamps lasted in total $96 \mathrm{~h}$, which is $1.5 \%$ of total observation time and $3 \%$ of the total feeding time. During swamp visits, all adult individuals and many older infants and juveniles ingested aquatic herbs. Among all of the aquatic herbs available in the swamps, bonobos focus on the two species analyzed in this study. One of them, the white water lily (Nymphaea lotus), is harvested in large quantities, and bonobos mainly ingest those parts of the plant that grow under water, while discarding flowers and leaves (Fig. 1). When feeding on the second species Juncus spp, bonobos ingest relatively small quantities, selecting the soft pith of the leaf base. 
Table 1 Mineral content of aquatic herbs (AHV), terrestrial herbs (THV), and fruit from trees and vines

\begin{tabular}{|c|c|c|c|c|c|c|c|c|c|c|c|c|}
\hline \multirow[t]{2}{*}{ Genus/species } & \multirow{2}{*}{$\begin{array}{l}\text { Plant } \\
\text { type }\end{array}$} & \multirow[t]{2}{*}{ sample } & \multirow[t]{2}{*}{$\mathrm{Mn}$} & \multirow[t]{2}{*}{$\mathrm{Ca}$} & \multirow[t]{2}{*}{$\mathrm{Zn}$} & \multirow[t]{2}{*}{$\mathrm{Mg}$} & \multirow[t]{2}{*}{$\mathrm{Na}$} & \multirow[t]{2}{*}{$\mathrm{Fe}$} & \multirow[t]{2}{*}{ K } & \multicolumn{3}{|l|}{1} \\
\hline & & & & & & & & & & $a$ & $\mathrm{~b}$ & c \\
\hline Nymphaea lotus & AHV & leaf & 470.23 & 8278.10 & 52.90 & 4559.68 & na & 605.71 & $23,774.29$ & na & na & na \\
\hline Nymphaea lotus & AHV & stem & 226.54 & 5035.00 & 60.69 & 5565.00 & na & 901.00 & $93,015.00$ & 1.23 & $1.05 \pm 0.06(5)$ & na \\
\hline Juncus spp. & AHV & pith & na & na & na & na & na & na & na & 7.99 & $7.53 \pm 0.15(5)$ & 7.14 \\
\hline Haumania liebrechtsiana & THV & pith & 193.80 & 1540.80 & 62.40 & 2742.40 & 35.20 & 62.70 & $43,880.70$ & 0.30 & 0.36 & na \\
\hline Dialium corbisieri & Tree & leaf & 54.77 & 924.02 & 28.55 & 1108.33 & 45.02 & 127.11 & $10,999.12$ & $<0.10$ & 0.01 & na \\
\hline Drypetes spp. & Tree & fruit & 50.26 & 694.02 & 21.45 & 1267.67 & 11.48 & 19.82 & $10,873.88$ & 0.10 & 0.08 & na \\
\hline Landolphia spp. & Vine & fruit & 74.62 & 807.88 & 67.95 & 782.24 & 22.83 & 49.36 & $13,289.26$ & $<0.10$ & 0.02 & na \\
\hline Gambeya lacourtiana & Tree & fruit & 17.07 & 339.90 & 12.40 & 365.95 & 15.35 & 19.60 & 8595.78 & $<0.10$ & 0.05 & na \\
\hline Parinari excelsia & Tree & fruit & 4.68 & 1023.85 & 5.80 & 865.37 & 29.31 & 24.48 & $12,986.86$ & $<0.10$ & 0.07 & na \\
\hline Dialium gossweiler & Tree & fruit & 74.83 & 975.17 & 18.11 & 1673.13 & 8.34 & 33.06 & 8919.70 & $<0.10$ & 0.01 & na \\
\hline Irvingia gabonensis & Tree & fruit & 84.40 & 1360.22 & 22.27 & 1333.04 & 25.06 & 26.21 & $15,258.96$ & $<0.10$ & 0.09 & na \\
\hline Mammea africana & Tree & fruit & 115.91 & 4070.57 & 14.39 & 3155.34 & 19.30 & 61.23 & $10,334.62$ & $<0.10$ & na & na \\
\hline
\end{tabular}

$\mathrm{a}=$ inductively coupled plasma mass spectrometry (ICP-MS) with prior ion chromatography

$\mathrm{b}=$ value obtained from Sandel-Kolthoff

$\mathrm{c}=$ value obtained from ICP-MS with prior alkaline extraction using tetramethylammonium hydroxide

Figures refer to weights in $\mathrm{mg} / \mathrm{kg}$ dry matter. Measures of iodine content with Sandel-Kolthoff are means \pm SEM and (in brackets) the number of repeated runs. All other figures represent means of duplicate and triplicate measurements of the same pooled sample na not available

\section{Discussion}

According to the World Health Organization (WHO) the continental part of the Congo basin is considered to be a region where natural sources of iodine are scarce (WHO Global data base [23]). This classification is based on survey data from human populations that showed a high prevalence of iodine deficiency symptoms and low values of urinary iodine excretion [24]. Introduction of iodized salt has improved the iodine status and reduced the appearance of iodine deficient symptoms amongst village populations [25]. This raises the challenging question of how ancestral human populations were able to meet their iodine requirements in this environment. Unlike many other human populations of the Congo basin, Efe pygmies show a low prevalence

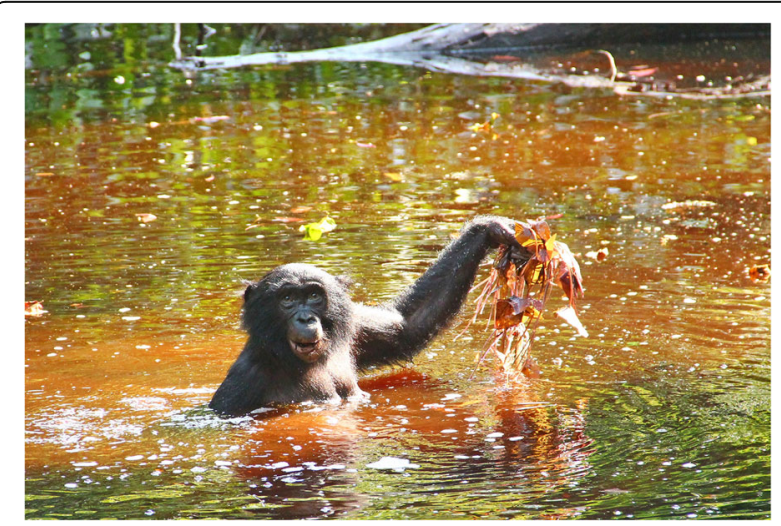

Fig. 1 Adult female bonobo retrieving water lillies (Nymphea lotus) from a back water (courtesy Zana Clay, LuiKotale Bonobo Project) of iodine deficiency symptoms [26], and it has been suggested that indigenous populations of the Central African forest may have acquired genomic adaptations including growth and height-restraints to low ambient levels of iodine [27]. Alternatively, ancestral human populations may have either relied on iodine obtained from other regions or may have notoriously suffered from iodine deficient symptoms. The results of our study show that the Congo basin is not devoid of natural sources of iodine per se. Instead, some species of aquatic herbs contain iodine concentrations that are almost equivalent to those of marine algae (see Table 1 in Teas et al. [28]). However, the accessibility of iodine to consumers is limited and varies with ambient levels, diet composition, and interactions among different nutrients [29]. Without corresponding information on the iodine status of wild bonobos it is difficult to tell how much iodine is actually obtained from ingestion of aquatic herbs. Yet, given the high concentration of iodine in aquatic herbs, consumers are likely to obtain substantial amounts of iodine even if accessibility of this plantderived iodine source is rather low.

Another point that must be considered is that we do not know to what extent the iodine concentrations measured in aquatic herbs at the field site of LuiKotale are representative of the entire Congo basin. Yet, our data challenge the general notion that the Congo basin is iodine depleted and demonstrate that the lowland forest offers natural sources of iodine in concentrations high enough to prevent iodine deficiency in humans. Given that these sources are exploited by contemporary 
populations of hominoid primates suggests that aquatic herbs could have served as an important source of minerals in general, and for iodine in particular, throughout the evolution of bonobos as well as for human populations immigrating into the central Congo basin.

Previous studies suggested that the consumption of rare plant foods by hominoid primates may reflect the need for micronutrients that are absent or rare in the plant-based diet of forest dwellers ([30] and references therein), but these studies do not consider iodine content as a driving force. However, taking an evolutionary perspective, it is reasonable to assume that iodine intake may have triggered the emergence of traits that differentiate hominoids from other primates. Experimental work has shown that primates respond to insufficient amounts of dietary iodine with symptoms that are similar to those of modern humans [31]. Even males of red deer living in iodine deficient areas suffer from reduced stag development, which is likely to reduce their fitness [32]. In contrast, wild rodents living under extreme iodine deficient conditions do not differ in their iodine status from populations that have sufficient access to iodine [33]. In this context, data from modern humans that indicate adaptations to low ambient levels of iodine raise the interesting question of to what extent are hominoid primates able to adapt to environmental variation in iodine supply.

One effect of low levels of iodine supply is reduced synthesis of thyroxine (T4), which coincides with a compensatory increase in triiodthyronin or T3 [7, 34, 35]. Different transporter systems facilitate the transfer of the iodothyronines T4 and T3 to target tissues. In case of low T4 availability, those cellular structures of the human brain will incur diminished thyroid hormone signaling that depends more strongly on local deiodinasedependent T3 generation and thus on a favorable cellular uptake of T4. Here, neurons with particularly pronounced astrocyte interactions appear to be most negatively affected [36]. Whether an improved supply of $\mathrm{T} 4$ versus T3 may have been an advantage regarding developmental neuron differentiation of hominins requires further research.

The results of the nutritional analyses presented above show that aquatic herbs can contain high concentrations of iodine and that bonobos consume such herbs with low frequency but regularly. Based on the results of this study, we can now address more specific questions about the iodine status of wild bonobos, such as the relationship between intake of iodine-rich herbs and urinary iodine measures, the impact of female reproductive status on iodine intake, and the effect of iodine rich plant intake by immatures on physical development. Consumption of aquatic herbs has been reported in other ape species [30], offering scope for cross-species comparisons of iodine content across the Congo basin and other landscapes inhabited by hominoids.

Major advances in the evolution of hominins are associated with brain supportive nutrients and iodine intake is thought to have set the benchmark for speciation, including the differentiation that accompanied the emergence of our own species [37]. Rich sources of iodine exist in coastal areas, wetlands, and areas of volcanic activity. Accordingly, evolutionary scenarios tend to associate the progressive development of brain size and cognitive skills to such areas. Accepting the notion that coastal areas offered a diet that triggered encephalization in hominins, the results of our study suggest that this need for dietary iodine would not have prevented ancestral hominins to invade continental forest habitats. Instead, consumption of aquatic herbs could have contributed to satisfying the iodine requirements of hominin populations that were primed by diets prevalent in coastal environments. However, results from diet examinations in contemporary humans show that high intake of animal protein goes along with high iodine ingestion even after taking into account dietary consumption and potentially iodized salt intake [38]. Thus, the combination of iodine-enriched aquatic herbs and increased animal protein intake may have set the stage for the progressive functional expansion of the human brain.

Apart from the relevance of aquatic herbs in the diet of contemporary hominoids and its putative function for prehistoric humans, the results of our study raise questions concerning the use of aquatic plants by contemporary human populations and the pathways of iodine in the larger environment of the Congo basin.

\section{Conclusions}

The continental part of the Congo basin is considered as a region where natural sources of iodine are thought to be scarce and where humans depend on supplementation of iodine. The area is also inhabited by hominoid primate species, and the lack of evidence for iodine deficiency symptoms in these species indicates that the natural diet provides sufficient amounts of iodine. The results of our study show that the Congo basin is not devoid of natural sources of iodine per se, that some species of aquatic herbs contain iodine concentrations that are almost equivalent to those of marine algae, and that bonobos (and perhaps other hominoid species) consume such iodine-containing herbs. Evolutionary scenarios align major developments of human evolution with environmental conditions of coastal areas offering a diet that triggered encephalization in hominins. The results of our study suggest that this need for dietary iodine would not have prevented ancestral hominins from invading continental forest habitats and that consumption of aquatic herbs could have contributed 
to satisfying the iodine requirements of hominin populations that were primed by diets prevalent in coastal environments.

\section{Methods}

\section{Study site and subjects}

Behavioral observations were collected from two habituated communities of wild bonobos occupying overlapping ranges in the LuiKotale forest at the western border of Salonga National Park, block south, Democratic Republic of the Congo [39]. For information on the size and demography of the two communities and ranging patterns see Fruth and Hohmann [40]. Both groups are habituated to the presence of human observers and are followed by teams of researchers and local assistants on a daily base. Studies on the nutritional ecology of the LuiKotale forest, and on the nutritional quality of plant foods started in 2002 and are ongoing. Systematic data on habitat use and feeding behavior have been collected since 2006 from the West community and since 2011 from the East community [40].

\section{Nutritional analyses}

Measures of iodine content are part of an ongoing study of assessing mineral content in bonobo plant foods by the lab of the Leibniz Institute for Zoo and Wildlife Research in Berlin. To obtain dry matter of plant samples in amounts that were sufficient for nutritional analyses, we collected fresh plant material from multiple sources (e.g. ripe fruit from the several trees and herbs from different locations) and pooled these samples after lyophilisation. Thus, the information on mineral content refers to measures of pooled samples of the same plant species and not to individual plants. Mineral content was assessed using an inductively coupled plasma optical emission spectrometer (model Optima 8000, Perkin Elmer, Rodgau, Germany) after microwave digestion (MLS 'START 1500' MLS GmbH, Leutkirch, Germany). Iodine content was measured with the catalytic technique of Sandell-Kolthoff [41] modified by Groppel [42] and Küblbeck [43]. Measurements of material from the same pooled sample were done in duplicate or triplicate. Iodine content was measured in plant food species that are representative of the diet of wild bonobos including fruit and leaves from woody plants, as well as terrestrial and aquatic herbs. Because measures of iodine are particularly sensitive to analytic methods, iodine content was also analyzed with two separate inductively coupled plasma mass spectrometry (ICP-MS) methods, one by the Institute for Düngemittel und Saatgut in Hameln with a prior alkaline extraction method employing tetramethylammonium hydroxide and the other by the Thüringer Landesanstalt für Landwirtschaft with prior ion chromatography [44].

\section{Abbreviations}

AHV: Aquatic herbaceous vegetation; C3 plants: Plants using a 3 carbon molecule for photosynthesis; C4 plants: Plants using a 4 carbon molecule for photosynthesis; CA: Calcium; Fe: Ferrum = mineral form of iron; I: Iodine; ICPMS: Inductively coupled plasma mass spectrometry; K: Kalium; kg: Kilogram; Mg: Magnesium; mg: Milligram; Mn: Mangan; Na: Natrium; na: Not available; SEM: Standard error of the mean; T3: Triiodthyronin; T4: Thyroxin; THV: Terrestrial herbaceous vegetation; WHO: World Health Organization; Zn: Zinc

\section{Acknowledgements}

The Institut Congolaise pour la Conservation de la Nature gave permission to conduct research at LuiKotale. We thank Heidrun Barleben for sample analyses, Zana Clay for contributing the photograph used in this paper, Verena Behringer and Andre Eger for stimulating discussions, Sean Lee for editorial support, and two anonymous reviewers for their constructive comments.

\section{Authors' contributions}

SO carried out the lab work, GH, BF and TR developed the study concept and analyseddata; GH and BF collected data and provided essential materials; all authors helped to draft the manuscript and approved the final version of the manuscript for submission.

\section{Funding}

Fieldwork has been supported by the Max-Planck-Society, the Centre for Research and Conservation, Antwerp (running costs of the field site), the L.S.B. Leakey Foundation (nutritional analyses), the National Geographic Society (ranging patterns), and The Volkswagen Foundation (nutritional analyses).

Availability of data and materials

The datasets used and/or analyzed during the current study are available from the corresponding author on request.

Ethics approval and consent to participate

Not applicable.

\section{Consent for publication}

Not applicable.

\section{Competing interests}

The authors declare that they have no competing interests.

\section{Author details}

${ }^{1}$ Max Planck Institute for Evolutionary Anthropology, Deutscher Platz 6, 04103 Leipzig, Germany. ${ }^{2}$ Leibniz Institute for Zoo and Wildlife Research, Alfred-Kowalke-Str. 17, 10315 Berlin, Germany. ${ }^{3}$ DONALD Study Center Dortmund, Institute of Nutritional and Food Sciences, University of Bonn, Heinstück 11, 44225 Dortmund, Germany. ${ }^{4}$ Faculty of Science, Liverpool John Moores University, Byrom Street, Liverpool L3 3AF, UK. ${ }^{5}$ Centre for Research and Conservation, Royal Zoological Society of Antwerp, Koningin Astridplein 20-26, B - 2018 Antwerp, Belgium.

Received: 12 October 2018 Accepted: 29 May 2019

Published online: 02 July 2019

\section{References}

1. Aiello LC, Wheeler P. The expensive-tissue hypothesis: the brain and the digestive system in human and primate evolution. Curr Anthropol. 1995;36:199-221.

2. Snodgrass JJ, Leonard WR, Robertson ML. The energetics of encephalization in early hominids. In: Hublin J-J, Richards MP, editors. The evolution of hominin diets. Dordrecht: Springer Netherlands; 2009. p. 15-29. https://doi.org/10.1007/978-1-4020-9699-0_2.

3. Crawford MA, Marsh D. The driving force: food, evolution and the future. London: Harper \& Row; 1989

4. Cunnane SC. Human brain evolution: a question of solving key nutritional and metabolic constraints on mammalian brain development. In: Cunnane SC, Stewart KM, editors. Human Brain Evolution: the influence of freshwater and marine food resources. Hoboken: Wiley; 2010;33-64. https://doi.org/10. 1002/9780470609880.ch3.

5. Simopoulos AP. Evolutionary aspects of diet: the omega-6/omega-3 ratio and the brain. Mol Neurobiol. 2011;44:203-15. 
6. Crockford SJ. Rhythms of life: thyroid hormone \& the origin of species. Victoria, B.C.: Trafford; 2006.

7. Venturi S, Begin ME. Thyroid hormone, iodine and human brain evolution. In: Cunnane SC, Stewart KM, editors. Human brain evolution: the influence of freshwater and marine food resources. Hoboken: Wiley; 2010.

8. Milton K. The critical role played by animal source foods in human (Homo) evolution. J Nutr. 2003;133:3886S-92S.

9. Cerling TE, Ehleringer JR, Harris JM. Carbon dioxide starvation, the development of C4 ecosystems, and mammalian evolution. Philos Trans R Soc B Biol Sci. 1998;353:159-71.

10. Leigh SR. Brain growth, life history, and cognition in primate and human evolution. Am J Primatol. 2004:62:139-64.

11. Aldridge K. Patterns of differences in brain morphology in humans as compared to extant apes. J Hum Evol. 2011;60:94-105.

12. Matsuzawa T. Comparative cognitive development. Dev Sci. 2007;10:97-103.

13. Whiten A, van Schaik CP. The evolution of animal "cultures" and social intelligence. Philos Trans R Soc B Biol Sci. 2007;362:603-20.

14. Hohmann G, Fowler A, Sommer V, Ortmann S. Frugivory and gregariousness of Salonga bonobos and Gashaka chimpanzees: the influence of abundance and nutritional quality of fruit. In: Feeding ecology in apes and other primates: ecological, physical, and behavioral aspects. Cambridge: Cambridge University Press; 2006;123-59.

15. Hernandez-Aguilar RA, Moore J, Pickering TR. Savanna chimpanzees use tools to harvest the underground storage organs of plants. Proc Natl Acad Sci. 2007;104:19210-3.

16. Boesch C, Head J, Robbins MM. Complex tool sets for honey extraction among chimpanzees in Loango National Park, Gabon. J Hum Evol. 2009;56:560-9

17. Sanz CM, Morgan DB. Flexible and persistent tool-using strategies in honeygathering by wild chimpanzees. Int J Primatol. 2009;30:411-27.

18. McGrew WC. Chimpanzee material culture: implications for human evolution Cambridge [England]; New York: Cambridge University Press; 1992.

19. Payne C, Mato B, Fruth B. Entomophagy in the area surrounding LuiKotale, Salonga National Park. Democratic Republic of the Congo Afr Study Monogr. 2016:37:1-12.

20. Stanford CB. The hunting apes meat eating and the origins of human behavior. Princeton, New Jersey: Princeton University press; 2001.

21. Hohmann G, Fruth B. New records on prey capture and meat eating by bonobos at Lui Kotale, Salonga National Park, Democratic Republic of Congo. Folia Primatol (Basel). 2008;79:103-10.

22. Malenky RK, Wrangham RW. A quantitative comparison of terrestrial herbaceous food consumption by Pan paniscus in the Lomako Forest, Zaire, and Pan troglodytes in the Kibale Forest, Uganda. Am J Primatol. 1994:32:1-12.

23. WHO, UNICEF, ICCIDD. Assessment of iodine deficiency disorders and monitoring their elimination. A guide for programme managers. WHO. 2007

24. Phillips DIW, Lusty TD, Osmond C, Church D. lodine supplementation: comparison of oral or intramuscular iodized oil with oral potassium iodide. A controlled trial in Zaire. Int J Epidemiol. 1988;17:142-7.

25. Vanderpas J-B, Moreno-Reyes R. Historical aspects of iodine deficiency control. Minerva Med. 2017. https://doi.org/10.23736/S0026-4806.17.04884-4.

26. Dormitzer PR, Ellison PT, Bode HH. Anomalously low endemic goiter prevalence among Efe pygmies. Am J Phys Anthropol. 1989;78:527-31.

27. López Herráez D, Bauchet M, Tang K, Theunert C, Pugach I, Li J, et al. Genetic variation and recent positive selection in worldwide human populations: evidence from nearly 1 million snips. PLoS One. 2009;4: e7888.

28. Teas J, Pino S, Critchley A, Braverman LE. Variability of iodine content in common commercially available edible seaweeds. Thyroid. 2004;14: 836-41.

29. Hurrell R F. Bioavailability of iodine. Eur J Clin Nutr. 1987;51 Suppl.:1S9-S12.

30. Kempf E. Patterns of water use in primates. Folia Primatol (Basel). 2009:80:275-94.

31. Mano MT, Potter BJ, Belling GB, Chavadej J, Hetzel BS. Fetal brain development in response to iodine deficiency in a primate model (Callithrix jacchus jacchus). J Neurol Sci. 1987;79:287-300.

32. Lehoczki R, Erdélyi K, Sonkoly K, Szemethy L, Csányi S. Iodine distribution in the environment as a limiting factor for roe deer antler development Biol Trace Elem Res. 2011;139:168-76.
33. Cabello G, Vilaxa A, Spotorno AE, Valladares J, Pickard M, Sinha A, et al. Evolutionary adaptation of a mammalian species to an environment severely depleted of iodide. Pflüg Arch - Eur J Physiol. 2003;446:42-5.

34. Paul T, Meyers B, Witorsch RJ, Pino S, Chipkin S, Ingbar SH, et al. The effect of small increases in dietary iodine on thyroid function in euthyroid subjects. Metabolism. 1988;37:121-4.

35. Kopp W. Nutrition, evolution and thyroid hormone levels - a link to iodine deficiency disorders? Med Hypotheses. 2004;62:871-5.

36. Visser TJ. Cellular uptake of thyroid hormones. In: De Groot LJ, Chrousos G, Dungan K, Feingold KR, Grossman A, Hershman JM, et al., editors. Endotext. South Dartmouth (MA): MDText.com, Inc.; 2000. http://www.ncbi.nlm.nih. gov/books/NBK285565/.

37. Crockford SJ. Thyroid rhythm phenotypes and hominid evolution: a new paradigm implicates pulsatile hormone secretion in speciation and adaptation changes. Comp Biochem Physiol A Mol Integr Physiol. 2003;135:105-29.

38. Remer T, Neubert A, Manz F. Increased risk of iodine deficiency with vegetarian nutrition. Br J Nutr. 1999;81:45-9.

39. Hohmann G, Fruth B. Lui Kotal - a new site for field research on bonobos in the Salonga national park. Pan Afr News. 2003;10:25-7.

40. Fruth B, Hohmann G. Food sharing across Borders: first observation of intercommunity meat sharing by bonobos at LuiKotale, DRC. Hum Nat. 2018;29:91-103.

41. Sandell EB, Kolthoff IM. Micro determination of iodine by a catalytic method. Mikrochim Acta. 1937;1:9-25.

42. Groppel B. Jodmangelerscheinungen, Jodversorgung und Jodstatus des Wiederkäuers (Rind, Schaf, Ziege). Karl-Marx-Universität; 1978.

43. Küblbeck C. Untersuchungen zur Jodversorgung von Hunden und Katzen in Frankreich. Ludwig-Maximilians-Universität; 2003.

44. Leiterer $M$, Truckenbrodt $D$, Franke K. Determination of iodine species in milk using ion chromatographic separation and ICP-MS detection. Eur Food Res Technol. 2001;213:150-3.

\section{Publisher's Note}

Springer Nature remains neutral with regard to jurisdictional claims in published maps and institutional affiliations.

\section{Ready to submit your research? Choose BMC and benefit from:}

- fast, convenient online submission

- thorough peer review by experienced researchers in your field

- rapid publication on acceptance

- support for research data, including large and complex data types

- gold Open Access which fosters wider collaboration and increased citations

- maximum visibility for your research: over $100 \mathrm{M}$ website views per year

At BMC, research is always in progress.

Learn more biomedcentral.com/submissions 